\title{
CrimRxiv
}

\section{Private Security's Accountabilities within Polycentric Assemblages}

Julie Berg, Clifford Shearing

Published on: Jun 23, 2021

License: Creative Commons Attribution 4.0 International License (CC-BY 4.0). 
